REVISTA DE DERECHO UNED, NÚM. 18, 2016

\title{
LA POTESTAD INSPECTIVA V/S LA AUDITORÍA PÚBLICA. OJEADA HISTÓRICA DENTRO DEL DERECHO ADMINISTRATIVO AMBIENTAL CUBANO
}

\author{
AUTHORITY INSPECTIVA AND THE PUBLIC AUDIT. \\ HISTORIC GLANCE WITHIN THE ADMINISTRATIVE \\ ENVIRONMENTAL RIGHT CUBAN
}

\author{
Alcides ANTÚNEz SÁNCHEZ ${ }^{1}$ \\ AMEd RAMírez SÁNCHEZ ${ }^{2}$
}

Resumen: El artículo realiza un examen sobre la labor de las Administraciones Públicas, a partir de la dimensión como Estado Vigilante, desde la tradicionalidad de la doctrina jurídica clásica constata que las dividió como actividad de policía, de fomento y de servicio público. Es un hecho que en las últimas décadas el Derecho Ambiental

\footnotetext{
${ }^{1}$ Licenciado en Derecho. Máster en Asesoría Jurídica. Profesor Auxiliar, imparte las materias Derecho Ambiental y Mercantil en la Facultad de Ciencias Económicas y Sociales. Universidad de Granma. El trabajo es parte de una investigación vinculada al control ambiental a través de la Auditoría Pública dentro de las formas de gestión por su vínculo con la Función Inspectiva en la República de Cuba, resultado de la Tesis Doctoral sobre el Control Ambiental a través de la Auditoría Pública. Miembro de la Liga de Abogados Ambientalistas. Miembro de la Sociedad Cubana de Derecho Constitucional y Administrativo y de la Sociedad Cubana de Derecho Procesal de la UNJC.

${ }^{2}$ Licenciado en Derecho, Universidad de Oriente, Cuba (Título de Oro). Profesor Asistente de Derecho Administrativo, Universidad de Granma, Cuba. Doctorando en Derecho Administrativo por la Universidad de Oriente, Santiago de Cuba. Máster en Derecho Constitucional por la Universidad Internacional Menéndez Pelayo y el Centro de Estudios Políticos y Constitucionales de Madrid (CEPC), España, (Becario del CEPC curso 2014-2015), Máster en Derecho Constitucional y Administrativo por la Universidad de Oriente, Cuba, 2013. Miembro de la Sociedad Cubana de Derecho Constitucional y Administrativo y de la Sociedad Cubana de Derecho Procesal de la UNJC
} 
se perfecciona, pero su aplicación sigue teniendo resultados no adecuados para su adecuada protección como un bien público de uso colectivo, requerido de un mayor control a través de la función inspectora, la que concluye con la ejecución de la auditoría pública en las formas de gestión al ser esta última más integral, en pos de conformar empresas amigables con el ambiente para transformar el escenario actual. Se hace un análisis a partir del proceso de reforma y actualización que se realiza por el Estado cubano en la economía, se estudian para ello la inspección ambiental y la auditoría ambiental como mecanismos o técnicas de control para coadyuvar a la protección del bien público ambiental que permita lograr el desarrollo sostenible y lograr con ello mejor calidad de vida y bienestar social.

Abstract: The article accomplishes an exam on the work of the Regional Government Bodies as from the dimension like Alert State, from the tradition of the juridical classical doctrine verify that you divided them like activity of policeman, of fomentation and of public utility. It is a fact than The Environmental right gets perfect in last decades, but his application keeps on having results made suitable for his adequate protection like a public property of collective use, once a bigger control through the show was called for inspector, the one that concludes with the execution of the public audit in the forms of step to the being this ends more integral, in pursuit of conforming friendly companies with the environment to transform the present-day scene. And analysis as from the process plucks up reform and bringing up to date that comes true for the Been Cuban in economy, they study for it the environmental inspection and the environmental auditing like mechanisms or techniques of control to collaborate to the protection of the environmental public property that it enable to achieve the sustainable development and to achieve with it better quality of life and social welfare.

Palabras clave: intervención pública, desarrollo social, control público, potestad inspectora, auditoría pública.

Keywords: Public intervention, social development, public control, authority inspector, public audit.

Recepción original: 18/02/2016

Aceptación original: 6/04/2016

\section{PRÓLOGO}

El desarrollo social de las últimas décadas ha sido un factor determinante en la definición del rol de lo público como mecanismo de dirección y control social. Esta situación se debe en buena medida a 
que el contenido de la actividad administrativa y la propia concepción de la Administración Pública han sido dos conceptos variables y no uniformes, consustanciales con el tiempo, al escenario geográfico, al régimen sociopolítico y en especial referencia dentro de este, a la intervención del Estado en las relaciones sociales en sus distintas modalidades.

Sin embargo, a pesar de las mutaciones genéticas de lo público, pervive la eficacia de aquellas palabras de FORSTTOFTH: «La Administración está llamada a hacer realidad los cometidos del Estado. Estos cometidos se determinan de acuerdo con la realidad social básica y las ideas políticas que individualizan el Estado; es decir, de acuerdo con el contenido sustancial de la Constitución. A este contenido tiene que estar orientada toda su actividad. La Administración necesita, por ello, una instancia directiva, la cual tiene su lugar estructural dentro de la Constitución. Con ello quedan diseñados la posición especial y el cometido del Gobierno del Estado...»3.

Dos fenómenos distintos al contexto de estas palabras como son el de la integración europea y la globalización hacen del Derecho Público un grupo de cánones cada vez menos distantes desde los diversos sistemas de Derecho ${ }^{4}$. Y con ello, se ha replanteado una y otra vez el rol del Estado y concretamente, de las Administraciones Públicas, quienes en los marcos de la exigencia de eficiencia económica ${ }^{5}$ han visto venir desplazados sus actividades tradicionales enfocadas en la prestación de servicios públicos para ser instancias de regulación, garantía y control ${ }^{6}$, con independencia de que mantengan bajo su abrigo competencial el desarrollo de actividades que revisten un marcado interés general o tengan naturaleza de servicio público ${ }^{7}$.

${ }^{3}$ FORSTHOFF, Ernst, «Tratado de Derecho Administrativo», traducción de Legaz Lecambra, Garrido Falla y Gómez de Ortega y Junje, Instituto de Estudios Políticos. España. 1958. p 30.

${ }^{4}$ Cfr. SCHMIDT-ASSMANN, Eberhard, «La teoría General del Derecho Administrativo como sistema. Objeto y fundamentos de la construcción sistémica», Instituto Nacional de Administración Pública, Marcial Pons, Ediciones Jurídicas y Sociales, S. A, Madrid, Barcelona, 2006, p 40 y ss, GUICHOT, Emilio, "Globalización Jurídica y Derecho Público. Recientes aportaciones en la doctrina europea» en Revista de Administración Pública, número 187, Centro de Estudios Políticos y Constitucionales, Madrid, enero-abril, 2012, pp. 305-326.

${ }^{5}$ VAQUER CABALLERIA, Marcos, «El criterio de la eficiencia en el derecho administrativo» Revista de Administración Pública, N. ${ }^{\circ}$ 186, Centro de Estudios Políticos y Constitucionales, septiembre-diciembre Madrid, España, 2011, pp. 91-135

${ }^{6}$ Cfr. SAUTER, Wolf, "Public Services in EU Law», Cambridge University Press, United Kingdom, 2015, p 29 y ss.,

${ }^{7}$ Cfr. PAREJO ALFONSO, Luciano, «Lecciones de Derecho Administrativo», Tercera edición revisada y actualizada, Tirant lo Blanch, Valencia, España, 2010, p 32 y ss. 
Es en esa dirección, que la menor intervención en la gestión directa de la actividad administrativa impuesta por lo grandes procesos liberalizadores se han volcado en torno a un necesario equilibrio, en pos de la regulación y el control de las crecientes modalidades de colaboración público privada, asegurando así la necesaria garantía que representa el cumplimiento de la juridicidad en las relaciones jurídicas administrativas ${ }^{8}$.

Como contrabalance, la retirada en la gestión directa de actividades de naturaleza administrativa, ha exigido la aplicación más coherente de las técnicas contenidas en la actividad de limitación o policía, de tradicional construcción desde la doctrina europea ${ }^{9}$, la que ha evolucionado hacia la ordenación y el control. Con ello se ha pretendido alcanzar una articulación de técnicas de intervención desarrolladas desde las potestades administrativas que se configuran a partir de la autotutela organizadora. De tal modo, a pesar que la ecuación de la fórmula de gestión se haya modificado, el resultado final de garantía y realización de los derechos fundamentales que tiene aparejado la realización del interés público, mantiene el ámbito de actuación, pero desde otro ámbito de incidencia, estableciendo límites y estándares en los niveles de actividad, por un lado, y controlando su cumplimiento, por el otro.

El artículo tiene como objetivo demostrar la distinción y semejanzas entre la función inspectiva y la auditoría pública dirigida a la protección del bien jurídico ambiental, como actividades de control ejecutadas por la Administración Pública dirigidas como sujeto activo a las formas de gestión estatal, a los sujetos privados y a los ciudadanos. Para ello se realiza un análisis de la potestad inspectora a partir

${ }^{8}$ Cfr. MIR PUIGPELAT, Oriol «El Derecho Administrativo Español en el Actual Espacio Jurídico Europeo» en VON BOGDANDY, Armin y MIR PUIGPELAT, Oriol, (Coords.), Ius Publicum Europaeum. El Derecho Administrativo en el Espacio Jurídico Europeo, Tirant lo Blanch, Valencia, 2013. P 219 y ss, CANTERO MARTÍNEZ, Josefa, «A vueltas con el ejercicio de potestades públicas y su ejercicio por los particulares. Nuevos retos para el derecho» en Revista española de Derecho Administrativo, Numero151/2011, Editorial Civitas, SA., s/p (BIB 2011 107$)$ administrativo.

${ }^{9}$ BONNARD, Roger, "Précis de Droit Administratif», $4^{\mathrm{TA}}$ Ed. Revue et mise au courant des Réformes Administratives, LGDJ, Paris, Francia, 1943, p 413 y ss, HAURIOU, Maurice, "Précis de Droit Administratif et Droit Public Generale», quatrième Edition, Librairie de Société de Recueil General de Lois \& Arrêts, Paris, 1904, p 585 y ss 533 y ss, RIVERO, Jean, Droit Administratif, Treiziéme Edition, Jurisprudence Genérale Dalloz, Francia, 1990, p 538, VEDEL, GEORGES, Derecho Administrativo, traducción de la 6t. a edición francesa por Juan Rincón Jurado, Editorial Aguilar S. A., Madrid, 1980, pp 661-687, 74. MAYER, Otto, «Derecho Administrativo Alemán», T II, Parte Especial. Poder de Policía y Tributario, traducción directa del original francés por Horacio H. Heredia y Ernesto Krotoschin, Editorial Depalma, Buenos Aires, 1949, p 3-36. 
de los criterios doctrinales; de la actividad de la auditoría pública, sus criterios doctrinales desde la dimensión económica, social y ambiental, los elementos que la distinguen y los puntos de coincidencia de ambas instituciones jurídicas abordadas en el artículo. Que culmina con el análisis de lo que concurre en el proceso de reforma y actualización del modelo económico y social cubano en pos de lograr conformar la empresa amigable con el ambiente para alcanzar el desarrollo sostenible.

\section{LA POTESTAD INSPECTORA DE LA ADMINISTRACIÓN PÚBLICA. UN ACERCAMIENTO A SUS CRITERIOS DOCTRINALES}

La inspección deviene en una técnica de intervención sobre la actividad administrativa de creciente utilidad. Su presencia ha desbordado los tradicionales ámbitos de actividades de gestión financiera, prestacionales de sanidad, higiene y educación, para ganar presencia en sectores más emergentes como la economía (pesca, agricultura), la industria, los servicios de interés general (recursos hídricos, electricidad y energía, telecomunicaciones, transporte), consumo, el medio ambiente y el urbanismo.

A ello, debe sumarse el hecho de que su contenido vincula a las más importantes instituciones del Derecho Administrativo, desde la actividad administrativa propiamente, pasando por su organización y la función pública, hasta los procedimientos y los actos administrativos, la potestad sancionadora, el control administrativo, la responsabilidad, entre otros.

Pero ello no indica que la inspección contenga una categoría jurídica de novedosa introducción en el Derecho Administrativo, todo lo contrario, su arraigo en la práctica de las Administraciones es en buena medida, consustancial al propio desarrollo de esta Ciencia. Sin embargo, los autores consideran que ha sido una "Cenicienta», pues los estudios teóricos en este campo no resultan abundantes en comparación con otras instituciones jurídicas y no es hasta décadas recientes que se encuentran artículos y monografías vinculadas al tema, hecho que habla de la necesidad de la sistematización doctrinal de su contenido para su futuro proceso de construcción.

Conjuntamente, en materia de regulación jurídica se asiste a una dispersión normativa ocasionada por una creciente reglamentación sectorial en término muchas veces no compatibles, que se agudiza 
con la carencia de una regulación general sistematizadora de sus elementos ${ }^{10}$. Tal referente se aprecia inclusive en los pronunciamientos de los máximos intérpretes y controladores de la Convencionalidad, la Constitucionalidad y la Legalidad; tendencias constatadas que en Cuba tiene coincidencia.

Es por ello que como bien sostiene REBOLLO PUIG desde la realidad Española, pero aplicable a disímiles contextos, «(...) una regulación de la inspección administrativa es especialmente necesaria por la elemental razón de que aquí el ámbito cubierto por la actuación administrativa sancionadora es más amplio que en otros países y que, en consecuencia, donde en éstos basta una regulación de la investigación judicial de los delitos, entre nosotros es muchísimo lo que depende de la inspección administrativa de las infracciones» ${ }^{11}$.

Conviene por ello entonces, valorar los elementos de las más importantes posiciones teóricas sostenidas al respecto. En tal sentido, un primer grupo identifica la inspección como una actividad, con referencias a los vínculos de la actividad sancionadora y la de control preventivo o represivo.

En esta vertiente destacan los criterios de SÁNCHEZ MORÓN, para quien la inspección es «(...) una actividad formalizada que tiene por finalidad verificar, igualmente con carácter preventivo o represivo, el cumplimiento de deberes u obligaciones, prohibiciones o limitaciones impuestas por la legislación vigente»12. Aquí destacan los elementos de la formalización de la actividad, su carácter preventivo o represivo y la comprobación del cumplimiento de la legalidad, sea cual sea la intervención.

Siguiendo esa línea, GARCÍA URETA la califica como «una actividad administrativa ordinaria de intervención, de carácter ejecutivo para la comprobación del ejercicio de derechos y obligaciones por parte de un particular, con el fin de determinar su adecuación al ordenamiento jurídico. Esta actividad incluye la recopilación de datos, la vigilancia, la investigación y, en especial, la verificación del desarrollo ordenado de la actividad de la que el particular sea titular» ${ }^{13}$.

${ }^{10}$ Cfr. REBOLLO PUIG, Manuel, «Propuesta de Regulación General y Básica de la Inspección y de las Infracciones y Sanciones Administrativas» en SAINZ MORENO, Fernando, (Director) Estudios para la reforma de la Administración Pública, $1 .^{\circ}$ edición, Editorial INAP, Madrid, España, 2004, p. 449.

${ }^{11}$ Ídem, p. 449.

${ }^{2}$ SÁNCHEZ MORÓN, Miguel, «Derecho Administrativo. Parte General», 6. ${ }^{\text {a ed., }}$ Editorial Tecnos, Madrid, España, p. 660.

${ }^{13}$ GARCÍA URETA, Agustín, «La potestad inspectora de las Administraciones Públicas», Editorial Marcial Pons, Ediciones Jurídicas y Sociales, S. A. Madrid, Barcelona, 2006. p. 29. 
Esta construcción para, como las anteriores que abordan el criterio de los derechos y las obligaciones impuestas por la legalidad al particular, se destacan los elementos de las fases de los procedimientos administrativos, y su carácter ejecutivo por encima del formal señalado por SÁNCHEZ MORÓN, con la cualificación del cumplimiento del principio de legalidad como adaptación al ordenamiento jurídico.

Un segundo grupo, suele encuadrarla como mecanismo de control posterior puramente. Así, pueden ser identificados los criterios de BERMEJO VERA, quien fundamenta el criterio de que: «(...) se habla de actividad, función o potestad de inspección, sin excesiva precisión en este momento, para identificar unas actuaciones, más o menos genéricamente previstas en el ordenamiento jurídico, que habilitan a las Administraciones públicas para llevar acabo funciones de comprobación o constatación del cumplimiento de la normativa vigente, en su sentido más amplio, esto es, incluidas muy especialmente las condiciones y requisitos de orden técnico, consecuencia inherente de la imposición que a determinadas personas, actividades, instalaciones, objetos y productos hacen ciertas normas jurídicas. El motivo principal de la dotación y ejercicio de estas funciones de inspección y control es, en cualquier plano, la seguridad.... ${ }^{14}$.

Esta resulta una de las definiciones más acabadas en la doctrina administrativa, que introduce un aspecto importante: las múltiples miradas de la inspección como potestad, actividad o función, aspecto que ha tomado diversos caminos, como veremos luego. En igual sentido, la caracterización técnica de la actividad inspectora se conjuga con la de legalidad para configurarse valoran los autores como un control de legalidad técnica.

En tercer lugar, se distingue una posición que la asocia como actividad auxiliar a otras. Desde esa línea, al decir de REBOLLO PUIG, "La inspección es una actividad administrativa auxiliar de otras porque siempre tiene por finalidad detectar hechos que deben dar origen al ejercicio de otras potestades administrativas: no sólo la sancionadora, como simplistamente puede pensarse, sino a otras muchas de intervención de entidades de crédito, de reintegro de subvenciones, de restablecimiento de la legalidad, etc. Aun así, ella misma cumple por sí sola una función de prevención general que refuerza la observancia de los debe-

${ }^{14}$ BERMEJO VERA, José, La Administración Inspectora, Revista de Administración Pública, número 147, Centro de Estudios Políticos y Constitucionales, España, 1998, pp. 40-41. 
res. $Y$, en cualquier caso, aunque auxiliar de otras, se presenta formalmente al margen de esas otras» ${ }^{15}$.

De tales posiciones, emanan algunas características relevantes que precisan ser sistematizadas.

1) La inspección administrativa ha sido vislumbrada desde una óptica tripartita, bien como potestad reconocida en el ordenamiento jurídico a la Administración Pública, bien como función pública desarrollada por inspectores (funcionarios), bien como técnica de intervención de actividad material de control o policía, que no resultan incompatibles entre estas, sino resultan diversas posiciones jurídicas del ciclo de la actividad inspectora (ente administrativo atribuido de potestades exorbitantes en régimen reglado, funcionario público habilitado competencialmente y actividad investigativa de hechos, documentación de información y comprobación).

Como potestad puede ser entendida como una técnica de atribución de poder, propia de la teoría general del Derecho y como expresión del principio de legalidad (juridicidad), que emana directamente del ordenamiento jurídico para el reconocimiento de una situación de poder de incidencia de los órganos de inspección hacia una actividad o sector de la actividad administrativa o particular, con el objetivo de producir efectos jurídicos derivados de la comprobación de la actividad con los criterios técnico legales, sin que ello genere de facto relaciones jurídicas, derechos o deberes; sino una sujeción al ordenamiento jurídico a partir de posiciones pasivas ${ }^{16}$.

${ }^{15}$ REBOLLO PUIG, Manuel, «La actividad de inspección» en CANO CAMPOS, Tomás, Lecciones y Materiales para el Estudio del Derecho Administrativo.» Tomo III. La Actividad de Las Administraciones Públicas. Volumen II. El Contenido, 1. ${ }^{\text {a }}$ ed., editorial Iustel, Madrid, España, 2009, p. 55

${ }^{16}$ Se sigue en este sentido el criterio de la doctrina italiana sistematizado POR GARCÍA DE ENTERRÍA y RODRÍGUEZ FERNÁNDEZ y extendido a parte importante de la doctrina española, Cfr. GARCÍA DE ENTERRÍA, Eduardo y FERNÂNDEZ RODRÍGUEZ, Tomás-Ramón. «Curso de Derecho Administrativo», T. I, 15. ${ }^{a}$ ed., editorial Thompson-Cívitas, Madrid, España, 2011, pp. 466 y ss., ZANOBINI, Guido, Curso de Derecho Administrativo, Volumen I, Parte General, traducción de la 5ta edición italiana (1949) por Héctor MASNATTA y actualizada con la 6ta edición por Francisco Humberto PICONE, Ediciones ARAYÚ, Buenos Aires, 1954, p 227 y ss., GIANNINI, Massimo Severo, «Derecho Administrativo», INAP, trad. Pos. ORTEGA, Luis, Vol Primero, Madrid, España, 1991, pp. 171 y ss, BACIGALUPO SEGGESE, Mariano, «Las potestades Administrativas», en CANO CAMPOS, Tomás, Lecciones y Materiales para el Estudio del Derecho Administrativo. Tomo III. La Actividad de Las Administraciones Públicas. Volumen I. La forma, 1. ${ }^{\circ}$ Ed., Iustel, Madrid, España, 2009, LINDE PANIAGUA, Enrique, «Fundamentos de Derecho Admimstrativo. Del Derecho del poder al Derecho de los ciudadanos», 2. ${ }^{\circ}$ Ed., UNED, Madrid, 2010, p 267 y ss, GAMERO CASADO, Eduardo y FERNÁNDEZ RAMOS, Severiano, Manual Básico de Derecho Administrativo. Séptima edición, Tecnos, Madrid, España, 2010, pp 58-59. 
Como parte del criterio la función del Derecho Administrativo, matizado por la arista subjetiva de la organización administrativa, se entiende como la acción administrativa desplegada por un funcionario (inspector), inserto en el tejido administrativo de forma estable, bajo las formas de ingreso y permanencia establecidas legamente para el cuerpo de inspección, que en ejercicio de las competencias profesionales aparejadas a su formación, eficacia y experiencia, realiza con objetividad y proporcionalidad un análisis de conformidad de las manifestaciones de la actividad inspeccionada con los requerimientos establecidos en las normas generales y reglamentarias de carácter técnico que ordenen el desarrollo de la actividad que se ejecuta ${ }^{17}$.

Como técnica de intervención de actividad material de control, tiene como fin la aludida verificación de cumplimiento de la actividad inspeccionada con el contenido de los deberes u obligaciones, prohibiciones y limitaciones reconocidas desde el orden legal o reglamentario para el desarrollo de la actividad, bien con carácter preventivo o posterior ${ }^{18}$.

2) Es de naturaleza individual, no depende ni requiere de la voluntad o del concierto del administrado ni de otros sujetos (en principio) para su plena eficacia y puesta en ejecución, incluso en aquellos casos en los que el título habilitante para el ejercicio de la potestad inspectora provenga o esté conectado con la participación voluntaria del administrado en una determinada relación jurídica de naturaleza administrativa (relación contractual de servicios públicos).

3) En relación al ámbito de inspección, la actividad puede desarrollarse hacia lo interno de la organización administrativa, como hacia lo externo, en la actividad de otras Administraciones o de los particulares $^{19}$.

4) Resulta una actividad de comprobación de legalidad (juridicidad) en la actividad de los particulares conforme a las reglas establecidas, bien desde disposiciones generales habilitadas con preferencia

${ }^{17}$ En este sentido se siguen los criterios básicos de la función administrativa establecidos por CASSESE, Sabino, "Las Bases del Derecho Administrativo», trad. pos., Luis Ortega, INAP, Madrid, España, 1994, pp 106-116, SANTAMARÍA PASTOR, Juan Alfonso, "Principios de Derecho Administrativo General», 2da Ed. Iustel, Madrid, España, 2009, p 641 y ss, PAREJO ALFONSO, Luciano, «Lecciones de Derecho Administrativo. Tercera edición revisada y actualizada», Editorial Tirant lo Blanch, Valencia, p 755 y ss, PARADA, Ramón, «Derecho Administrativo. Organización y empleo público», Decimosexta Ed, Marcial Pons, 2003, Madrid, España, p 381 y ss, BLANQUER, David, Curso de Derecho Administrativo I. Los sujetos y la actividad, Tirant Lo Blanch, Valencia, España,2006, pp 358-359.

${ }^{18}$ Cfr. SÁNCHEZ MORÓN, Miguel, ob. cit., p 660.

${ }^{19}$ Cfr. REBOLLO PUIG, Manuel, ob. cit. ult., p. 57 
mediante Reserva de Ley, o bien desde normas reglamentarias para el desarrollo de la actividad inspeccionada ${ }^{20}$.

5) Sus efectos tienen un carácter instrumental al ejercicio de otras potestades administrativas como son la sancionadora o la procedimental, o en una actividad en concreto desarrollada por la Administración, con independencia de la fórmula de gestión, lo mismo en el procedimiento autorizatorio, en el tributario o el sancionador, en el inmobiliario, o de otra administración sectorial.

Sin embargo, debemos afirmar que posee una autonomía propia que las diferencia de aquellas como mera fase o instrumento, pues obedece a fines y funciones propias que, aunque coadyuvan a aquellas, desbordan el contenido de estas, pues en reiterados casos se desarrolla para obtener una actualización del estado de funcionamiento de la actividad inspeccionada y en consecuencia planifica una actividad tendente a la mejor progresiva de la calidad y la eficiencia del servicio.

De ahí que la potestad de inspección tenga como fin la comprobación de la certeza de juridicidad; expresando el resultado de la intervención de control, mediante evidencia documental certificante del estado de compatibilidad de la actividad administrativa con sus parámetros de ordenación ${ }^{21}$.

6) Es una función de carácter técnico, para el ejercicio de esta función se requiere de un alto nivel de cualificación y habilitación técnica para su desempeño, de ahí que su desarrollo atienda a factores como la competencia, formación del inspector, conocimientos y aptitudes demostradas en la actividad a realizarse. Ha sido precisamente ese carácter tecnocrático, el que ha influenciado en los años recientes la externalización en el desarrollo de esta actividad desde formas de gestión indirecta, a partir de mecanismos de colaboración público-privada $^{22}$.

7) Es una potestad de ejercicio reglado, donde no cabe discrecionalidad en su aplicación. Debe de ajustarse a un canon de objetividad, eficiencia, transparencia y responsabilidad, que permitan asegurar, desde la planificación y control de su ejercicio, la debida neutralidad, probidad y cumplimiento estricto de la juridicidad por parte del inspector ${ }^{23}$.

${ }^{20}$ Cfr. BLANQUER, David, ob. cit., p. 358, RIVERO ORTEGA, Ricardo, «Derecho Administrativo Económico», Editorial Marcial Pons, Madrid, España, 2007, p 162

${ }^{21}$ Cfr. BLANQUER, David, ob. cit., p 360

${ }^{22}$ Cfr. ídem., pp 360-361; cfr. FERNÁNDEZ RAMOS, Severiano, «La actividad administrativa de inspección: el régimen jurídico general de la función inspectora», Editorial Comares, Granada, España, 2002, pp. 54-55

${ }^{23}$ Cfr. ibidem., p 362 
8) Tiene un efecto fedatario sobre la actividad inspeccionada. Esta facultad es reconocida a los notarios públicos, se desarrolla en la inspección mediante las Actas de Inspección, son verdaderos informes que certifican el estado de compatibilidad de la práctica administrativa en relación con la ordenación jurídica de la actividad, a las que el ordenamiento procesal les atribuye el carácter vinculante y directo en la fase probatoria, por la certeza y la veracidad que la competencia del inspector aporta en el Acta que se notifica al sujeto inspeccionado ${ }^{24}$.

9) En algunos supuestos, sobre todo en casos de gestión indirecta, pueden resultar una actividad de carácter oneroso para el inspeccionado, porque así lo requiera para la certificación de hechos o circunstancias relativas a su actividad o por un tercero con interés procesal o técnico, creado en virtud de una relación orgánica. A ello se debe agregar la posible preferencia de un cuerpo de inspectores ajenos a la actividad inspeccionada que brinde un mayor nivel de neutralidad en las valoraciones técnicas que puedan ser emitidas en el Acta de Inspección ${ }^{25}$.

Sentadas tales características, resultaría conveniente por parte de los autores referirnos a los principios que informan la actividad inspectora. En primer lugar, el principio de legalidad (juridicidad), este deviene en el eje estructural de esta potestad, pues la comprobación de conformidad se realiza desde los criterios técnicos establecidos para la actividad inspeccionada. Su desarrollo, atendido a los criterios reglamentarios y legales, impone por un lado una verificación de lo normado en el desarrollo de la actividad inspeccionada, y por otro, una función inspectora acorde al canon de legalidad, de vinculación positiva, mediante el cual se asegura la sujeción de la actividad a la norma jurídica administrativa.

De igual forma, debe destacarse uno de los principios de mayor invocación en el Derecho Público, el de proporcionalidad. Según la aplicación de este principio deben de establecerse un justo balance de ponderación entre la calidad e intensidad de la función inspectora en relación a la eficiencia de la actividad inspeccionada, de modo tal que esta no resulte inoperativa o en estado de inactividad como consecuencia de la intervención de la función inspectora ${ }^{26}$.

En igual sentido, vinculado al ámbito subjetivo de la función inspectora, el principio de objetividad o imparcialidad, este impone una actitud y desempeño inmaculado del inspector, ajeno a favoritismos, parcia-

\footnotetext{
${ }^{24}$ Cfr BLANQUER, David, David, ob. cit., p. 359

${ }^{25}$ Cfr. BLANQUER, David, ob. cit, pp. 361

${ }^{26}$ Cfr. RIVERO ORTEGA, Ricardo, ob. cit., p 162
} 
lizaciones de índole políticas, administrativas o motivadas por dádivas económicas monetarias o en especie. La función inspectora debe ser desarrollada de modo independiente, incluso, sin predispociones o indicaciones de superiores jerárquicos de fuerzas políticas o administrativas externas. En resumen, debe de deberse solo al estricto deber de comprobación de compatibilidad de la legalidad con la actividad inspeccionada.

Por último, nos referimos al principio de confidencialidad de la información obtenida y deber de secreto y discreción de los inspectores. Bajo la égida de este principio de actuación de la función inspectora, se destaca una de las exigencias fundamentales para los funcionarios que desarrollan la actividad, la del manejo adecuado y exclusivo de la información obtenida conforme a los resultados de la inspección. Así ha de exigirse que esta no sea manejada por terceros ajenos a la relación de inspección o con los beneficiarios directos de sus resultados, pues en caso contrario podrían generarse lesiones incidentales directas a la actividad inspeccionada e imputable a la inspección por la violación de algún derecho reconocido a personas naturales o jurídicas.

Pero no basta la ordenación de estos principios rectores de la actividad, al resultar preciso para su desarrollo de una adecuada ordenación de las facultades derivadas de la potestad de inspección. Es así, que siguiendo a MUÑOZ MACHADO, quien señala que entre las normas sectoriales, como tendencia, son reconocidas las potestades de «(...) requerir información, la exhibición de documentos, la comparecencia de los inspeccionados ante las oficinas públicas, la facultad de entrada en fincas, instalaciones o recintos de propiedad particular, la toma y análisis de muestras, las visitas de inspección, etc. Inclusive se prevé la facultad de requerir aquellos datos necesarios para las finalidades de la inspección que sobre un sujeto puedan estar en poder de terceros o de otras Administraciones públicas» ${ }^{27}$.

Pero estas potestades deben ser ejecutadas desde un prisma de proporcionalidad, de modo tal que no afecten de modo irrazonable el ejercicio y disfrute de derechos fundamentales de los inspeccionados, como por ejemplo el derecho a la intimidad, que, al decir de RIVERO ORTEGA, «(...) es el derecho que más seriamente puede verse afectado por técnicas consistentes sobre todo en la recopilación de datos e informaciones. Pero también la igualdad, no siendo aceptable la focalización

${ }^{27}$ Cfr. SÁNCHEZ MORÓN, Miguel, ob. cit., p 661 
de las intervenciones inspectoras en sujeto determinado, de forma arbitraria o discriminatoria» ${ }^{28}$.

Pero no agota su posible incidencia negativa en el derecho a la intimidad, sino que puede generar estados lesivos a los derechos desde el resultado de la actuación como la inviolabilidad del domicilio, del secreto de las comunicaciones, o de la protección de los datos de carácter personal. Por otro lado, puede generar fricciones con los derechos de toda persona a no declarar contra sí mismo y del derecho a obtener información sobre sus derechos, cuestión que data una doctrina jurisprudencial importante ${ }^{29}$.

Los autores valoran como la inspección constituye una actividad material de la Administración, esta tiene lugar a través de un despliegue de medios personales y materiales para realizar las comprobaciones que correspondan. Es una actividad técnica, realizada por funcionarios públicos cualificados y bajo ciertos procedimientos y estándares de actuación. Constituye en sí misma un acto trámite, dado que su realización sirve a decisiones administrativas ulteriores. Es una auténtica potestad de la Administración Pública. Su titularidad es completamente pública.

Como técnica de intervención administrativa, responde al mecanismo o medio que se emplea por la Administración Pública para lograr determinados fines. Es, por tanto, una actividad esencialmente instrumental. La particularidad de la inspección radica en que resulta ser una técnica doblemente instrumental, al servicio de la eficacia del ordenamiento jurídico y de ciertos actos administrativos (su finalidad inmediata) y al servicio de la protección de los intereses generales de la comunidad (su finalidad mediata).

El ejercicio concreto de la potestad de inspección implica la formación de una relación jurídica entre la Administración y el ciudadano. La relación jurídica de inspección es aquella que se da entre un órgano de la Administración que tenga atribuido el ejercicio de dicha potestad y un particular que se relaciona de alguna manera con el objeto de la inspección. El sujeto activo de la relación jurídica de inspección corresponde a un órgano de la Administración del Estado que ostente la potestad para ejercer funciones inspectivas o fiscalizadoras.

\footnotetext{
${ }^{28}$ RIVERO ORTEGA, Ricardo, ob. cit., p 162, SÁNCHEZ MORÓN, Miguel, ob. cit., p 662 .

${ }^{29}$ Cfr. SÁNCHEZ MORÓN, Miguel, ob. cit. p. 662
} 
Al ser la inspección una función pública, su ejercicio debe quedar reservado, en primer lugar, a los funcionarios públicos. Es así, que con todas las crecientes necesidades experimentadas por la Administración en el control de la técnica y sus riesgos se han planteado nuevos dilemas en torno a la forma de organización de la inspección y a los recursos con que cuenta para ser ejecutada eficazmente por la Administración Pública.

Los inspectores pueden llegar a tener un conocimiento elevado respecto de la aplicación y cumplimiento de las normas jurídicas y de los actos administrativos que se regulan a un determinado sector. Por lo mismo, son portadores de información valiosa para la configuración de nuevas modalidades, planes o programas de inspección, que tengan en consideración las particularidades propias de la realidad frente a la cual ellos se enfrentan en el ejercicio de sus funciones inspectivas.

Se aprecia así, como el principio de prevención no sólo está asociado a la inspección como técnica de intervención sino que, en general, resulta predicable de innumerables otras técnicas relacionadas con la ordenación de diversas actividades económicas y sociales. Es un principio general que rige en la actividad de la Administración. Con la inspección, primordialmente, se pretende evitar o rechazar los peligros que pudieran afectar al orden público. Así, el tradicional binomio ordenación-sanción contempla un nuevo matiz -intermedio, si se quiere- protagonizado por la prevención.

En este sentido, la inspección es útil por dos razones. Primero, porque otorga una herramienta -el conocimiento- al legislador y a la Administración para el diseño de nuevos mecanismos que eviten la producción de daños en el actual contexto de la sociedad del riesgo. Segundo, porque produce un efecto intimidatorio sobre los ciudadanos que no son sujetos directos de ella, pero que sí pueden serlo en un futuro próximo. La inspección es, como advierten algunos, «una advertencia de control permanente del cumplimiento de obligaciones y deberes».

Sus dos funciones primordiales se constatan a través de la comprobación o verificación y la tutela de los intereses generales. Por ello en la doctrina administrativista más actual, se ha caracterizado a la potestad de inspección como una actividad unilateral desarrollada por la Administración Pública para la comprobación del ejercicio de derechos y obligaciones por parte de un particular, con el fin de determinar su adecuación al ordenamiento jurídico. Ella incluye la recopilación de datos, la vigilancia, la investigación y, en especial, la 
verificación del desarrollo ordenado de la actividad que el particular sea titular.

La potestad de inspección es una forma de intervención administrativa, unilateral, de carácter material e interlocutoria de decisiones administrativas ulteriores, es realizada con la finalidad de comprobar la adecuación del ejercicio de derechos y obligaciones de los particulares al ordenamiento jurídico y a los actos administrativos que los rigen. Al ser una potestad pública, su atribución debe realizarse por ley. Sus características son: la atribución que hace la ley de una potestad a la Administración puede ser reglada o discrecional, la potestad fiduciaria o potestad-función, esto es, que debe ejercerse en función de un interés distinto al de su titular, la potestad preventiva y correctora y la potestad autónoma de la potestad sancionadora.

Los principios que informan a la potestad inspectora son el de legalidad, responsabilidad, eficiencia, eficacia, coordinación, oficialidad, impugnabilidad, control, probidad, transparencia y el de publicidad en el desarrollo de esta función inspectiva.

Son sujetos pasivos en la relación jurídica de inspección, serían todas las personas naturales o jurídicas que resulten obligadas al cumplimiento de las normas y de los actos de la Administración que rigen a la actividad inspeccionada. El objeto de la relación jurídica de inspección puede consistir en cualquier actividad, objeto o entidad regulada por el Derecho, la actividad sometida al cumplimiento de ciertos requisitos o condiciones para su correcto ejercicio, ya sea que tales requisitos y condiciones estén establecidos en leyes, reglamentos o en los concretos títulos habilitantes con los cuales deba contar la actividad. El objeto de la inspección nunca recae directamente en personas, puesto que estas sólo son titulares o responsables de las actividades inspeccionadas. El prestar testimonio o declaración en torno al desarrollo de una actividad no las transforma en el objeto mismo de la inspección.

Es frecuente que una misma actividad pueda ser objeto de inspecciones múltiples. Ello ocurre en el control que la Administración Pública ejecuta a las actividades agrícolas, a las turísticas, a las educacionales, las recreativas, de transporte, entre otras; las cuales están sujetas a la actividad de inspección realizada por diversos órganos administrativos. Por ejemplo, el transporte interurbano está sujeto a la inspección técnica vehicular, a la inspección sobre los impuestos que deben pagar sus propietarios, a la inspección sobre las normas de seguridad que deben cumplirse en el transporte de pasajeros, a la inspección laboral sobre las horas que cada conductor puede trabajar, entre otros controles que se le realizan. 
En el caso de la inspección ambiental, se han ideado mecanismos que coordinan la acción fiscalizadora de la Superintendencia del ramo y de los organismos sectoriales, para que sus inspecciones no signifiquen una duplicación de funciones administrativas y no afecten el normal desarrollo de las actividades inspeccionadas por la Administración Pública para proteger el bien público ambiental por ser un bien de uso colectivo, el que hay que preservar para las futuras generaciones.

\section{LA AUDITORÍA PÚBLICA. CRITERIOS DOCTRINALES DENTRO DEL DERECHO ADMINISTRATIVO ECONÓMICO Y EL AMBIENTAL}

Abordar la Auditoría Pública como temática poco tratada en el Derecho Público y en especial en Cuba por parte del gremio de juristas dedicados a la investigación en temas administrativos, económicos y ambientales es todo un reto para los autores de este artículo, ya sea por la importancia que reviste la aplicación de manera adecuada de la función inspectiva y la auditoría al ser esta más integral dentro del proceso de reforma y actualización del modelo económico y social en Cuba, en pos de alcanzar el desarrollo sostenible que contribuya a una mejor calidad de vida y al bienestar social de los ciudadanos.

Esta actividad de control, configurada en la doctrina, al ser una de las actividades más importantes que ejercita la Administración Pública, sus destinatarios serían las formas de gestión sujetas a acciones de control por la norma legal que la regule, estando obligados a mantener sistemas de control interno conforme a sus características, competencias y atribuciones institucionales. Su finalidad es mantener, controlar y evaluar la efectividad del sistema en las instancias de dirección, señalado por autores de la talla de GORDILLO ${ }^{30}$, DROMI $^{31} \mathrm{Y}$ MUÑOZ MACHADO ${ }^{32}$.

Su importancia, se aprecia en la comprobación de las políticas del Estado en la preservación de las finanzas públicas y el control económico administrativo, incorporándose la dimensión ambiental en la década de los 90 del siglo XX, ponderada en el siglo XXI ante

${ }^{30}$ GORDILLO, Agustín, Tratado de Derecho Administrativo, 8. ${ }^{\text {a }}$ edición, Editorial Macchi, Argentina, 2006.

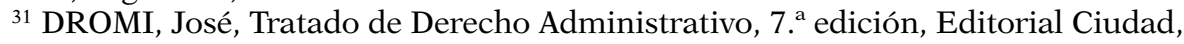
Argentina, 1998.

${ }_{32}$ MUÑOZ MACHADO, Santiago, Tratado de Derecho Administrativo y Derecho Público en General, Editorial Iustel, España, 2011. 
las consecuencias negativas generadas por el cambio climático, analizados en el último conclave internacional en Paris de 2015, al decir de autores como PAREJO ALFONSO, DELPIAZZO, PARADA y NIETO ${ }^{33}$.

Su iter histórico, se enmarca a partir de ser reconocida por las Entidades Fiscalizadoras Superiores (EFS) en el año 1995 del siglo pasado como una herramienta de gestión, otros estudios contables consideran su génesis vinculada a la Contabilidad y a la Auditoría Social, la misma está relacionada a la Responsabilidad Social Empresarial. De igual forma, la práctica de la auditoría, reconocida como una actividad de control y como una herramienta técnica de gestión, de amplia aplicación por parte de las EFS, al reconocerse ambas denominaciones para su ejecución por los auditores, su evolución se materializa en correspondencia a las áreas geográficas donde se aplica, y al nivel de desarrollo tecnológico de la industria.

Al analizarse los conceptos de los Organismos Internacionales que intervienen en las regulaciones en materia contable como la Asociación Americana de Contabilidad, la define como: ...«proceso sistemático para obtener y evaluar de manera objetiva las evidencias relacionadas con informes sobre actividades económicas y otros hechos relacionados. Su finalidad consiste en determinar el grado de correspondencia del contenido informativo con las evidencias que le dieron origen, para determinar sí en dichos informes se han elaborado observando los principios establecidos para el caso"...

La Cámara Internacional de Comercio, la reconoce como: ...«herramienta de gestión que comprende una evaluación sistemática, documentada, periódica y objetiva del funcionamiento de la organización ambiental. Prevé la implantación de gestión, así como los equipos de control necesarios con objeto de facilitar el control de gestión de las prácticas medio ambientales y declarar la observancia de la política de la Compañía de acuerdo con la normativa medio ambiental. Es el examen metódico que implica análisis y comprobaciones de las prácticas y procederes ambientales de una empresa o parte de ella. Este término de auditoría es sinónimo de revisión y verificación de diversos aspectos de una empresa»...

${ }^{33}$ DELPIAZZO, Carlos, Desafíos actuales del control, Editorial F. C. U., Montevideo, 2001; PAREJO ALFONSO, Luciano, Derecho Administrativo, Editorial Ariel, Barcelona, 2003; PARADA, Ramón, Derecho Administrativo, tomo I Editorial Marcial Pons, Madrid, 1997, pp. 534 y ss.; NIETO, Alejandro, Algunas precisiones sobre el concepto de policía, Revista de Administración Pública, número 81, España, 1976; CONVENCIÓN INTERNACIONAL DE PARIS DEL CAMBIO CLIMÁTICO, Francia, 2015. 
La Entidad Fiscalizadora Superior, la define como: la herramienta técnica de gestión para realizar la evaluación sistemática, documentada, periódica y objetiva de la efectividad de la organización auditada; la gerencia y los equipos ambientales para proteger el medio ambiente con un mejor control de las prácticas ambientales y la evaluación. Para cumplir las políticas ambientales de la empresa y las normativas legales, a partir de la institucionalización de la tutela ambiental en el desarrollo normativo que ha tenido.

\section{1 ¿Es considerada como una Actividad de Control, de Servicio Público, de Fomento o de Gestión Económica?}

$\mathrm{Al}$ responder estas interrogantes, los autores lo inician a partir del análisis de como esta actividad de control al ser esta una de las actividades más importantes de la Administración Pública, sus destinatarios son los sujetos sometidos a las acciones de control que por Ley se establece.

En materia de protección ambiental se aprecia como este tipo de control ha mutado, se valora en su aplicación de otros mecanismos de control que se le han ido incorporando en el transcurso de estos años, conocidos desde la doctrina como técnicas de tutela ambiental, realizadas a través de la aplicación del control interno, la fiscalización, la inspección, la auditoría, en el ordenamiento ambiental, en la actividad de información y la de educación ambiental.

Estos mecanismos pueden ser preventivos, para esto se establece la aplicación de instrumentos de control como: la autorización, aprobación, permisos, licencias, concesiones y otras. Los de control ambiental, se ejecutan a través de la auditoría ambiental, la policía ambiental, la supervisión ambiental y otros. Son aplicados para mejorar la conciencia ambiental e identificar los riesgos dentro de estas empresas para el desarrollo sostenible, a partir del principio de juricidad.

Todos estos conceptos, principios y elementos establecidos desde la doctrina administrativa relacionada con otras ramas del Derecho, este tipo de actividad de control deberá estar sustentada en ellos; en los ordenamientos jurídicos revisados se le reconoce como actividad de control y de servicio público. Como servicio público conlleva en sí acciones de control para medir su eficacia y eficiencia de las actividades auditables ambientales en las formas de gestión, como elementos de actividad pública visibles en la empresa estatal -sujeto estatal-.

Dentro de la materia medio ambiental, pudiera ser conformado a través del ordenamiento ambiental como parte del desarrollo urbanístico, con la licencia ambiental, la Evaluación de Impacto Ambiental, el Sistema de Inspección Ambiental y la recogida de los desechos só- 
lidos; todos tributan a la ejecución de la auditoría ambiental por su vínculo administrativo-ambiental.

La Administración Pública al practicarla para preservar el bien jurídico ambiental como bien de utilidad pública la realiza de forma obligatoria a través de un plan, se valora por los autores el vínculo que posee con la inspección y la potestad sancionadora que tiene la Administración Pública con sus funcionarios ante sus faltas por cometer daños a los recursos naturales del Estado.

Culmina todo este proceso con la entrega del resultado del informe final de la auditoría, sí cumple con las regulaciones y exigencias para ser reconocida como una empresa responsable con el ambiente, le certifican con la ecoetiqueta-certificación ambiental a los productos y servicios que realiza.

Como actividad de gestión económica, se analiza el uso de los instrumentos económicos considerados por la Derecho Administrativo Ambiental como la alternativa para atenuar los efectos de la problemática ambiental al modificar las conductas de producción y de consumo al concebirlas como empresas sostenibles.

Para ello, se aprecia como aparece en este escenario la alternativa jurídico-económica con el uso e implementación del tributo ambiental, elemento este utilizado para obtener un desarrollo limpio en relación con el principio de quien contamina paga desde el Derecho Ambiental. Su vínculo con la actividad de control practicada a las formas de gestión, es implementada y controlada por el Fisco en normativas tributarias afines al vertido ambiental generado en la actividad productiva o de servicios, ello abre el camino para utilizar nuevos instrumentos de protección con es el impuesto ambiental con la promoción de la Investigación + Desarrollo, la Etiqueta-certificación ambiental y la Auditoría ambiental como el control que da fin a todo este proceso ${ }^{34}$.

Como fomento ambiental, es el estímulo promovido por la Administración Pública para que las empresas sean menos contaminadoras, es regulado en normas jurídicas a través de Leyes de Fomento en los ordenamientos jurídicos, en atención al principio de juridicidad. En los países de Hispanoamérica se constata el reconocimiento de estímulos fiscales por la doctrina ambiental a través de impuestos o reformas fiscales ambientales como se citó.

${ }^{34}$ ANTÚNEZ SÁNCHEZ, Alcides, Actualización del modelo económico cubano para el ordenamiento jurídico en el desarrollo del Derecho Ambiental patrio, Revista Multiciencias, número 3, Venezuela, 2015, pp. 1-27. 
Son utilizados como instrumentos de mercado aplicados al transporte híbrido o eléctrico, en el reciclaje del plástico, en el control de la deforestación boscosa, en el tratamiento al agua potable y los desechos sólidos, en la conservación de la biodiversidad y en el uso de combustibles fósiles para modificar la matriz energética. Se vincula con la reingeniería de procesos en la industria a través de las tecnologías al final del tubo y con los encadenamientos productivos, señalado por autores como RÍOS GUAL ${ }^{35}$ y OSPINA DUQUE ${ }^{36}$.

Ello ha permitido desde la doctrina ambiental consultada por los autores, apreciar dos variables, una a través de la competitividad empresarial y otra en la protección ambiental con la entrega de instrumentos de acreditación ambiental al decir de MORA RUIZ ${ }^{37}$, MARTÍN MATEO ${ }^{38}$ Y SANZ RUBIALS ${ }^{39}$, estos permiten distinguir el tránsito desde la actividad de limitación u ordenación -policía- hacia la de fomento en este siglo XXI, fortalecida con la aparición en todo este escenario de las normas EMAS y la ISO 26000 en su dimensión ambiental al fomentarse la empresa amigable con el ambiente.

Los autores aprecian que la función inspectiva se configura dentro de las acciones de control que ejecuta la Administración Pública; empero la auditoría pública se configura como una actividad de control ejecutada por el Estado, es también reconocida como una actividad de servicio al ejecutarla de forma indirecta a través de sociedades mercantiles que ejercitan el servicio de la auditoría, es considerada como una actividad de gestión económica y de fomento, toda vez que es un instrumento de mercado para que las empresas sean más competitivas al obtener la etiqueta-certificación ambiental.

Aunque las nuevas tendencias de la función inspectiva en la Unión Europea en esta actividad inspectiva se esté ejercitando por sujetos privados, los que están requeridos de títulos habilitantes y la cualificación profesional de la actividad contratada, en pos de abarcar otros escenarios que la Administración Pública no controla ante la falta de capital humano.

\footnotetext{
${ }^{35}$ RÍOS GUAL, Josep, La reingeniería aplicada al mundo empresarial del siglo XXI, Revista de Empresas, España, 2007.

${ }^{36}$ OSPINA DUQUE, Rodrigo, La reingeniería de procesos: una herramienta gerencial para la innovación y mejora de la calidad en las organizaciones, Revista de Psicología y Administración de Empresas, España, 2011, pp. 3-34.

${ }^{37}$ MORA RUÍZ, Manuela, La gestión ambiental compartida: función pública y mercado, Revista Catalana de Derecho Ambiental, número 4, España, 2012, pp. 1-29.

${ }^{38}$ MARTÍN MATEO, Ramón, La ecoauditoría, Boletín de Estudios Económicos, número 150, España, 1993.

${ }^{39}$ SANZ RUBIALS, Iñigo, El mercado de derechos a contaminar, $1^{\text {era }}$ edición, Editorial Lex Nova, España, 2007.
} 


\subsection{Elementos que distinguen la función inspectiva de la auditoría Pública en materia ambiental}

Se aprecia por los autores que con la aplicación de instrumentos contables e incentivos fiscales la auditoría ambiental se ha desarrollado como una institución jurídica, ha permitido con ello la configuración del trinomio de la contabilidad como instrumento de las ciencias contables, del derecho desde su dimensión socio-económica al mutar hacia la auditoría ambiental, necesitada de una adecuada y necesaria ordenación jurídica, en razón de su importancia para proteger el medio ambiente y la economía; por lo que se considera que no podrá estar divorciada como herramienta de gestión de la potestad inspectora por ser más integral, debido a la información que le aportan otros saberes, como es el caso de la ciencia contables que tributan hacia la configuración del Derecho Ambiental Administrativo.

Los elementos analizados «up supra», permiten a los autores razonar que la Auditoría se distingue de la actividad inspectiva como potestad de la Administración Pública, toda vez que la función de Inspección tiene como objeto proteger la legalidad, la vigilancia y la fiscalización al revisar el nivel de observancia por parte de los sujetos obligados a su obediencia, coinciden en que ambas solicitan títulos habilitantes para su ejercicio. Son ambas ejecutadas a través de un plan anual con procedimientos específicos, en el caso de la ambiental está dirigida a los ecosistemas de interés de la autoridad ambiental, se inspecciona el resultado de las medidas dejadas en la licencia ambiental otorgada como respuesta de la Evaluación de Impacto Ambiental practicada o por las denuncias públicas recibidas por la autoridad ambiental, su alcance es limitado posición asumida por autores como BERMEJO VERA ${ }^{40}$, REBOLLO PUIG ${ }^{41}$, FERNÁNDEZ RAMOS ${ }^{42}$ y MIRANDA HERNÁNDEZ ${ }^{43}$.

La doctrina consultada desde las ciencias jurídicas en el Derecho Administrativo por los autores, define a la función inspectora, como la actividad ejercida de forma directa por la propia administración in

${ }^{40}$ BERMEJO VERA, José, La Administración Inspectora, Revista de Administración Pública, número 147, Centro de Estudios Políticos y Constitucionales, España, 1998, pp. 1-20

${ }^{41}$ REBOLLO PUIG, Manuel, La actividad inspectora, Editorial Iustel, España, 2011.

${ }^{42}$ FERNÁNDEZ RAMOS, Severiano, La inspección ambiental, Revista Medio Ambiente y Administración Local, España, 2012, pp.

${ }_{43}$ MIRANDA HERNÁNDEZ, Gloria, La potestad inspectora de las Administraciones Públicas, Revista Cuadernos de Inspección del Territorio, España, 2012, pp. 1-22. 
situ, con carácter aleatorio, discrecional y esencial, ligada al ejercicio de la potestad sancionadora.

Esta función inspectiva es una función de control configurada a una entidad por la complejidad de los riesgos que deben afrontarse por la sociedad actual. Esta potestad inspectora reconocida como policía administrativa es ejercitada de forma directa por la Administración Pública como una función de control, se configura a una entidad por la complejidad de los riesgos que deberá afrontar al tener un alcance horizontal.

Empero, la auditoría es más abarcadora como evaluación a los bienes públicos que la inspección por ser integral, ella le permite a los empresarios obtener una evaluación como empresa amigable con el ambiente al evaluar la eficacia y eficiencia del SGA como un primer elemento y contrapartida de la actividad inspectora. Esta también revisa la implementación dentro de las formas de gestión la aplicación y ejecución del presupuesto contable en materia ambiental dentro del sistema contable establecido en el ordenamiento jurídico, es ejecutada por auditores habilitados por el órgano de control, en su práctica se aplican los procesos y procedimientos de auditoría pública, se evalúa la observancia de la legalidad, el cumplimiento y la aplicación de las normas y los principios contables que desde el Derecho Ambiental ${ }^{44}$ y los de Auditoría Pública regulados en los ordenamientos jurídicos y por la INTOSAI la informan ${ }^{45}$, posiciones concebidas como resultado de la producción científica de autores como GORDILLO $^{46}$, SANZ RUBIALS ${ }^{47}$, NOGUEIRA LÓPEZ ${ }^{48}$, FERNÁNDEZ DE GATTA SÁNCHEZ ${ }^{49}$ y ANTÚNEZ SÁNCHEZ.

Esta auditoría es ejecutada conforme a un plan conformado por la EFS, comprende los lugares ambientales o áreas críticas con problemas de contaminación generados por las diferentes actividades desa-

${ }^{44}$ ANTÚNEZ SÁNCHEZ, Alcides, The principles of Environmental Law that inform environmental audit, the role of the SAI in the environmental area, Revista del Tribunal de Cuentas de la Unión, número 132, Brasil, 2015, p. 57

${ }^{45}$ ANTÚNEZ SÁNCHEZ, Alcides, La auditoría ambiental: Una revisión y propuestas en clave de su función pública y dimensión empresarial, Revista Iberoamericana de Contabilidad de Gestión, número 26, España, 2015, pp. 3-27

${ }^{46}$ GORDILLO, Agustín, Tratado de Derecho Administrativo, $8^{\text {va }}$ edición, Editorial Macchi, Argentina, 2006.

${ }^{47}$ SANZ RUBIALS, Iñigo, El mercado de derechos a contaminar, $1^{\text {era }}$ edición, Editorial Lex Nova, España, 2007.

${ }^{48}$ NOGUERIA LÓPEZ, Alba, Ecoauditorías, intervención pública ambiental y autocontrol empresarial, Editorial Marcial Pons, España, 2000.

${ }^{49}$ FERNÁNDEZ DE GATTA SÁNCHEZ, Dionisio, Las auditorías ambientales, Editorial Tirant lo Blanch, España, 2008. 
rrolladas en áreas rurales, cuencas, bahías, áreas naturales protegidas. Permite a los auditores identificar los diversos sectores que tengan competencias ambientales.

Las actividades dentro de la evaluación realizada incluye las que se realizan en la empresa auditada, asociadas con el manejo o contención de sustancias peligrosas, el control a los materiales y residuos con propiedades corrosivas, explosivas, tóxicas, inflamables o de algún modo contaminadoras y en los procesos o instalaciones que generen otras formas de contaminación ambiental. Como auditoría, en su proceso de ejecución revisa la observancia de la legislación y de la normativa ambiental por parte del sujeto auditado. Verifica variados aspectos como el uso del agua, la contaminación del aire, la disposición y el manejo de los residuos peligrosos y no peligrosos, la contaminación del suelo y del subsuelo; las descargas de agua residual, los procesos y los servicios industriales, el almacenaje de las materias primas y los residuos peligrosos, como las fuentes de emisión a la atmósfera.

La auditoría también evalúa la información relativa a la región donde está ubicada la industria auditada. Los mapas de localización de las instalaciones, otras industrias y colindancias, los planos de edificios e instalaciones, el tipo de construcción y el drenaje utilizado; se valora también por los auditores la participación ciudadana en la práctica de la evaluación ambiental como causas lógicas entre las problemáticas detectadas y la evaluación realizada se aprecia cómo esta institución jurídica es introducida por los países a partir de la firma de Convenios y Acuerdos internacionales con la INTOSAI ${ }^{50}$. Luego es introducida en los derechos internos a través de leyes orgánicas ambientales, de la auditoría y de la propia auditoría ambiental.

Se aprecia como su aplicación se vincula a otras normativas jurídicas en materias como las de la Administración Pública Ambiental, las Orgánicas de la Administración, las de Gestión ambiental, de Responsabilidad ambiental, de Control de la contaminación ambiental, de la Salud, del Agua, de la Biodiversidad, de los Parques nacionales, Agrarias, Ordenanzas municipales, de Ordenamiento ecológico, de Asentamientos humanos, de Metrología y Normalización, de Instrumentos económicos ambientales, de Fomento ambiental, en la Investigación científica y en la Educación ambiental.

${ }^{50}$ INTOSAI, Evolución y tendencias de las auditorías ambientales en el mundo, ONU, 2010. 
La ejecución de la auditoría ambiental es complementada en su aplicación por el equipo auditor que la realiza con la aplicación de las normas ISO 14000 y 19011. En conjunto podrá ser exigible la responsabilidad a los auditados al ser formulada la denuncia en las Fiscalías ambientales con el informe de la auditoría practicada ante la inobservancia de las políticas ambientales. La solución final del conflicto se realizará en sede judicial por parte de los Tribunales ambientales.

Los autores se incorporan a la postura de reconocer a la auditoría ambiental como la actividad de control que responde a las necesidades sociales. Es la herramienta susceptible de integrarse en la realización de las revisiones clásicas que se establecen por otras ramas de la economía industrial, esto le ha permitido integrarse a otras tipologías de auditorías como son las de legalidad, la financiera, la de cumplimiento y la de gestión, las que revisan en sus programas auditores aspectos vinculados con la protección ambiental, al brindar a los empresarios una mejor información en la materia ambiental y responden a las necesidades sociales como meta hacia la sostenibilidad para el desarrollo de la empresa.

$\mathrm{Al}$ ser realizada en base a criterios como al nivel de importancia y de urgencia de los problemas ambientales detectados, al alcance y complejidad de las actividades que realizan las formas de gestión, la influencia en el ambiente, al volumen de las emisiones de contaminación y al historial de los problemas ambientales. Identifica los elementos que enmarcan a la auditoría ambiental, al ser practicada en dependencia de las condiciones que la enmarquen, de los objetivos específicos que la motivan y del nivel de desarrollo que la organización empresarial a auditarse.

Esta actividad de control, comparte un objetivo común, entregar información documentada y validada sobre diferentes aspectos de la situación ambiental de la entidad auditada al identificarse los riesgos e impactos asociados, el examen y la evaluación de las prácticas existentes para mejorar el desempeño ambiental, permitirá comprobar el respeto a la legislación y los estándares ambientales de relevancia. La evaluación de la gestión ambiental realizada a las formas de gestión en razón de los principios básicos que la comunidad internacional ha reconocido para lograr una gestión ambiental eficaz y eficiente, al contar con módulos y herramientas que permitan a las sociedades proteger el derecho de las personas a disfrutar de un ambiente sano para su desarrollo, salud y bienestar social, a través de dispositivos 
que permitan a cualquier persona tener acceso a la justicia ambiental, como lo es el proceso de la auditoría ambiental ${ }^{51}$.

Se aprecia por los autores que las reformas energéticas y de los recursos naturales realizadas en América Latina en los sectores de la economía, la salud, la ciudadanía y el ambiente tributan a la ejecución de políticas sostenibles, permitirán conocer al equipo auditor el grado de economía, eficiencia y eficacia, la calidad e impacto en la planificación, el control y el uso de los recursos naturales, la conservación y la protección ambiental como características fundamentales en todo este proceso de planeación y práctica de esta actividad de control. Permitirá con ello el acceso a los empresarios a coberturas financieras mediante la póliza ambiental, al decir de autores de la talla de VIGURI PEREA ${ }^{52}$, CABEZA ARES ${ }^{53}$, ANTÚNEZ SÁNCHEZ ${ }^{54}$ y LORENZETTI ${ }^{55}$.

Los elementos subjetivos que se distinguen en esta relación jurídica administrativa serían el auditor -auditores certificados que pertenecen a las EFS, a las sociedades mercantiles- y los auditados -formas de gestión estatal y no estatal- integrado por técnicos, juristas y científicos, no identificados de manera adecuada dentro de la normativa jurídica vinculada a la actividad de la auditoría ambiental. Por ello, esta actividad de control se aprecia cómo evalúa el SGA, sí el mismo satisface los criterios del control contable y de la ingeniería ambiental, en cumplimiento de la norma en relación a las actividades que ejecuta el sujeto auditado.

Esta evaluación permitirá identificar y analizar los riesgos para alcanzar los objetivos, las metas propuestas y las posibles alternativas para darle solución in situ. El SGA está considerado como uno de los elementos que se certifica en las empresas en el área tecnológica, este

${ }^{51}$ ANTÚNEZ SÁNCHEZ, Alcides, Disquisiciones teóricas, doctrinales y exegéticas sobre la praxis de la auditoría como función pública, dirigida a la protección del bien público ambiental para la empresa ecológica, Revista Dos Tribunais Thomson Reuters, número 951, Brasil, 2015, pp. 17-52

${ }^{52}$ VIGURI PEREA, Alberto, La responsabilidad en materia medio ambiental, la auditoría ambiental y el seguro, Revista Española de Seguros, número 5, España, 2010, pp. 21-43

${ }^{53}$ CABEZA ARES, Alberto, Los seguros de responsabilidad civil medio ambiental en la obligación de reponer y restaurar el medio ambiente alterado, Editorial Trivium, España, 2003.

${ }^{54}$ ANTÚNEZ SÁNCHEZ, La auditoría pública con enfoque ambiental y el tributo ambiental. Aplicación e implementación en Cuba, Revista internacional Legis de Impuestos, número 64, Colombia, 2015, pp. 110-143.

${ }^{55}$ LORENZETTI, Ricardo, Teoría del Derecho Ambiental, $1^{\text {era }}$ edición, Editorial Porrúa, México D. F., 2008. 
recoge los requisitos relativos a la implementación de un sistema de protección ambiental al capacitar a la organización y permitir con ello formular la política y los objetivos de mejoras continuas como elemento clave, el mismo necesita un presupuesto financiero que permita su mantenimiento y reparación programada. Por lo que deberán ser observados los requisitos legales y la información sobre los impactos ambientales generados por las formas de gestión en el desarrollo de su política ambiental en una nación.

Los elementos objetivos que recoge el informe de la auditoría luego de formalizado el contrato de servicio público son: el cumplimiento de los parámetros de las tecnologías limpias, la implementación de las normas ISO 14000, 19011, 26000 y las EMAS, el uso del SGA, el impacto ambiental generado al medio ambiente, y la implementación de la contabilidad ambiental, el que se informa al sujeto auditado al concluir. En su ejecución por el equipo auditor aplica un programa de auditoría ambiental (transversalidad) en relación con el escenario a auditarse, concluye con la entrega del informe conforme a las etapas evaluadas y se entrega de la etiqueta-certificado ambiental, vinculada con las normas sustantivas en materia de metrología y normalización.

En su ejecución, la auditoría ambiental tiene en cuenta las formalidades acorde a la forma de gestión en que se realiza y al sujeto activo que la ejecuta, la realizada por la Administración como actividad de control inicia con la notificación inicial al auditado. La ejecutada por sociedades mercantiles de auditoría como servicio público requerirá del contrato como servicio público.

Los elementos formales a incorporarse en el informe final serían: la identificación de los sujetos, el contenido a auditar, el resultado de las acciones de control ambiental en torno a ejes como el de la tecnología, la contabilidad, la responsabilidad empresarial -ambiental-, la situación legal, el plan de acciones de control y la certificación ambiental. El equipo auditor implementa en su ejecución las directrices para la auditoría ambiental de la EFS, las normas ISO 14000, 19011, 26000 y las EMAS, los parámetros de las tecnologías limpias, la implementación del SGA, las normas y los principios de contabilidad y de la auditoría pública ${ }^{56}$.

Todo esto permitirá hacer un paneo del comportamiento que ha tenido la dimensión ambiental dentro del proceso de reforma del mo-

\footnotetext{
${ }^{56}$ ANTÚNEZ SÁNCHEZ, Alcides. El tratamiento jurídico de la etiqueta-certificación ambiental. Regulación en el Derecho Cubano, Revista Iberoamericana de Derecho Ambiental y los Recursos Naturales, número 18, Argentina, 2015, pp. 1-25.
} 
delo económico por la Administración Pública, al utilizar la función inspectiva y la de auditoría ambiental.

\section{LA ADMINISTRACIÓN PÚBLICA COMO ENTE VIGILANTE EN LA DIMENSIÓN AMBIENTAL, UNA MIRADA EN EL PROCESO DE REFORMA DEL MODELO ECONÓMICO CUBANO EN LA SEGUNDA DÉCADA DEL SIGLO XXI}

En la nación cubana, luego de constatado como es el tratamiento doctrinal en Hispanoamérica, se aprecia que su reconocimiento parte de los postulados constitucionales establecidos en los artículos 10, 27 y 69; a partir de que el 27 consagra la protección ambiental como una función pública del Estado. Toda vez que técnicamente, a la vez que se habilitaron los órganos competentes para que intervengan en la protección ambiental inspirados en el desarrollo sostenible, se ordenó la aplicación de dicha habilitación con el objetivo de «hacer más racional la vida humana y asegurar la supervivencia, el bienestar y la seguridad de las generaciones actuales y futuras» con lo que la solidaridad en términos de equidad inter e intrageneracional, la racionalidad y la sostenibilidad al trascender al texto constitucional cubano ${ }^{57}$.

No obstante el primer referente a partir de la institucionalización en la nación cubana aparece la Ley n. ${ }^{\circ} 1323$ de 1976, de Organización de la Administración Central del Estado, atribuyó al Comité Estatal de Ciencia y Técnica por el Decreto-ley n. ${ }^{\circ} 31$ de 1980 el establecimiento, la dirección y el control del Sistema Nacional de Protección del Medio Ambiente y el Uso Racional de los Recursos Naturales y por el Acuerdo del Consejo de Ministros de igual fecha, se creó la Comisión Nacional de Protección del Medio Ambiente y Conservación de los Recursos Naturales. Esquema institucional que se mantuvo hasta la promulgación del Decreto-ley n. ${ }^{\circ} 118$ de 1990 con apego a la Ley n. 33 de 1981, el que dispuso la creación del Sistema Nacional de Protección del Medio Ambiente y del Uso Racional de los Recursos Naturales y de una Comisión Nacional como la instancia coordinadora de la gestión ambiental con la participación de todos los órganos y organismos estatales, empresas, cooperativas, organizaciones políticas, sociales y de masas y de la ciudadanía en general.

Coexistiendo con la distribución de competencias previas respecto a los recursos naturales y subsistemas ambientales. Empero la auto-

${ }^{57}$ Constitución de la República de Cuba. G. O. Extraordinaria No. 3 de fecha 31 de enero de 2003. 
ridad ambiental a través de la potestad inspectora controló los ecosistemas de interés del país dando cumplimiento a las políticas públicas para proteger el medio ambiente. Con posterioridad, con la creación del Ministerio de Ciencias, Tecnología y Medio Ambiente, como organismo de la Administración Pública, con su sustento legal en el Decreto-ley n. ${ }^{\circ} 147$ de 1994 y en la Ley n. ${ }^{\circ} 81$ de 1997, este tiene el encargo público de garantizar la adecuada obediencia de las políticas y la normativa ambiental «ecuación para la vida» para comprobar y evaluar el cumplimiento del mandato legal. Para ello fueron creadas instituciones que han permitido incorporar nuevas funciones, muchas de ellas con un fuerte peso específico en la protección de la diversidad biológica y en la aplicación de las herramientas de gestión, ejecutada por inspectores estatales designados como funcionarios públicos por la Autoridad Ambiental, requeridos del título habilitante para el ejercicio de la potestad inspectora (técnicos de nivel medio y superior, juristas y científicos), con una identificación oficial y numeración a cada inspector. Ello permite ponderar que hay un Estado Vigilante en la materia ambiental en el país.

Los autores aprecian como fue el Ministerio de Ciencias, Tecnología y Medio Ambiente el que ha ejecutado a través de la función inspectora regulada en la Ley n. ${ }^{\circ} 81$ de 1997 en todo el país. Existen otros organismos dentro del entramado de la Administración Pública patria que en este mismo íter ejercitan la función inspectiva en la protección ambiental por su interdisciplinariedad y transdisciplinariedad, realizada a través de la inspección sanitaria ejecutada por el Ministerio de Salud Pública, el que evalúa el componente ambiental y el respeto de las ordenanzas sanitarias ${ }^{58}$; el Ministerio del Interior en relación a la obediencia de la seguridad laboral; el Ministerio de Economía y Planificación para el control de la política pública y el desarrollo urbanístico; el Ministerio de Trabajo y Seguridad Social para el control de la seguridad y la política laboral (ambiente laboral); el Ministerio de la Agricultura en relación a la política forestal, agraria, la medicina veterinaria, el Ministerio de Transporte para el control del transporte automotor (contaminación atmosférica, acústica y lumínica); uno de los últimos cuerpos de inspección en crearse ha sido el de los Consejos de la Administración Local en los municipios dedicados al control administrativo.

${ }^{58}$ RAMÍREZ SÁNCHEZ, Amed, ANTÚNEZ SÁNCHEZ, Alcides. La responsabilidad administrativa derivada de la inspección estatal sanitaria en Cuba. Una mirada a su régimen jurídico sancionador desde la lucha contra el dengue, Revista Derecho y Cambio Social, número 27, Perú, 2015, pp. 2-27. 
En el desarrollo normativo patrio tiene su soporte jurídico en el Decreto-ley n. ${ }^{\circ} 100$ de 1987, de la Inspección Estatal y cada organismo establece sus regulaciones internas a través de actos administrativos, por ello el artículo 1, señala que la inspección estatal consiste en la fiscalización del cumplimiento de las disposiciones y normas jurídicas vigentes llevadas a cabo por los organismos centrales de la Administración del Estado dentro de su propio sistema o en el ejercicio de su función rectora, o por los órganos locales del Poder Popular a través de sus dependencias administrativas sobre las actividades administrativas, de producción y de servicios.

Ello permite señalar el vínculo que esta potestad inspectiva posee con la exigencia de la responsabilidad administrativa, y la multiplicidad de disposiciones jurídicas que coexisten en este sentido, que permiten ponderar la necesidad de que se promulgue un Código Contravencional a futuro y que sea actualizada la Ley Ambiental en consecuencia, toda vez que es considerado que el marco regulatorio complementario no garantiza la adopción de enfoques preventivos adecuados aparejados a la indisciplina tecnológica que impera en la mayoría de las formas de gestión del sector estatal cubano al ser esta la mayoritaria, aspectos que deberán ser tenidos en cuenta en la futura actualización normativa. Su sustento se establece en la Resolución n. ${ }^{\circ} 103$ del 2008 del Ministerio de Ciencias, Tecnología y Medio Ambiente, esta se constriñe para la protección de los ecosistemas de interés del país.

También se aprecia como interviene en todo este control ambiental la Fiscalía General de la República, a tenor del artículo 27 constitucional y el artículo 42 de la Ley n. ${ }^{\circ} 81$ de 1997, regulan la función especial que posee este órgano en relación a la actuación fiscal para la tutela ambiental y el cumplimiento de la legalidad comprobado con la acción de la Verificación Fiscal. Los autores consideran que los otros organismos de la Administración Pública que ejercitan la potestad inspectora en la nación no la ejecutan de manera adecuada en su mayoría con apego a la norma; a pesar de que en los medios de comunicación de forma periódica se divulgan los temas ambientales y las acciones a tomar para protegerlo y preservarlo, empero no hay percepción del riesgo de una manera adecuada.

Los autores valoran las irregularidades en relación con la función inspectora que tributa a la contaminación ambiental generada por las formas de gestión, por ausencia de Sistemas de Gestión o por inadecuados tratamientos de estos donde los hay, lo que ocasiona vertido 
industrial visible en los procesos en las industrias, hospitales, empresas y otras instalaciones del sector estatal.

Se aprecia que en las formas de gestión no hay un uso adecuado de los medios de protección y en muchas de estas hay ausencia de estos ante la falta de presupuesto. Es también visible en el transporte automotor por los años de explotación no acorde con la norma internacional como potenciales contaminadores al ambiente al expeler gases producto de la combustión del combustible que utilizan, hay también una apreciada obsolescencia tecnológica de más de 50 años de explotación en las industrias, y que en muchas no son implementadas tecnologías limpias. Pero se reitera que la propia norma ambiental establece que la prioridad en la nación de la función inspectiva en materia ambiental es a los ecosistemas de interés.

En la materia de Auditoría Pública, se valora que en la reforma del modelo económico los estudios realizados a partir de la primera década del siglo XXI permitieron conocer la nueva decisión a nivel de Estado para crear la Contraloría General de la República en Cuba (CGR), como el nuevo órgano de control supremo, sustentado en la Ley n. ${ }^{\circ} 107$ de 2009, al amparo de los artículos 9 y 75 constitucionales; es así, que a este órgano le corresponderá ejercitar el más alto control estatal ambiental en cumplimiento del mandato legal.

No obstante, es el Reglamento de la CGR del 2010, complementada en las directrices del 2013 de este órgano, el que regula la auditoría ambiental como proceso y procedimiento para evaluar la actuación de las formas de gestión, las que hoy no se corresponden de manera adecuada en su mayoría con los problemas ambientales declarados en la Estrategia Nacional Ambiental, en el Programa Nacional de lucha contra la contaminación del medio ambiente y en el informe presentado por la Oficina Nacional de Estadísticas e Información sobre el Panorama Ambiental cubano, ante las conductas no proporcionales de las respuestas dadas por los actores competentes al realizarse la función inspectora, el control, la fiscalización y la auditoría.

Es así, que al analizar la Ley n. ${ }^{\circ} 107$, se señala en su artículo 11, donde se refiere que la auditoría es un proceso sistemático, realizado de conformidad con normas y procedimientos técnicos establecidos, consistente en obtener y evaluar objetivamente las evidencias sobre las afirmaciones contenidas en actos jurídicos o de carácter técnico, económico, administrativo u otros, con el fin de determinar el grado de correspondencia entre esas afirmaciones, las disposiciones legales vigentes y los criterios establecidos. 
El control es definido dentro de esta norma jurídica como el conjunto de acciones que se ejecutan para comprobar la aplicación de las políticas del Estado, así como del cumplimiento del plan de la economía y su presupuesto, y la Supervisión es el acto de inspección, investigación y comprobación que se realiza con la finalidad de velar por el cumplimiento de las disposiciones legales vinculadas con la actividad económico-financiera, preservar la disciplina y la integridad administrativa, así como prevenir y detectar actos de corrupción administrativa; sobre la base de intereses estatales y a partir de las informaciones que se reciban por cualquier vía, en especial las provenientes del pueblo, vinculadas con la ilegalidad en el control y uso de los recursos del Estado y actos de corrupción administrativa.

Se considera como los funcionarios designados para ejercer esta función pública requieren de una habilitación oficial, esta se obtiene al realizar un examen de suficiencia académica en este órgano de control, el que le permite obtener a posterior la inscripción en el Registro de Auditores de la nación, al obtenerse la certificación que los acredita para esta potestad (técnicos, juristas y cientistas).

Permite señalar a los autores que las causales que han conllevado al país para que tenga acumulado todas las situaciones ambientales adversas han sido los patrones de producción utilizados, el consumo y el uso de los recursos aplicados inciden en la contaminación, la degradación de los suelos, la pérdida de diversidad biológica, la carencia, disponibilidad y calidad del agua potable, y la afectación de la cobertura forestal, de ahí la necesidad de transformarlos y orientarlos hacia modelos de sostenibilidad ambiental adecuados, expresados en el Plan de Lucha contra la contaminación, difundido por el Ministerio de Ciencias, Tecnología y Medio Ambiente.

Son identificados entre los principales problemas en relación con la eficiencia en el uso de los recursos dentro de la Estrategia Ambiental Nacional, como son: la sostenibilidad de la producción y el consumo en el ámbito nacional, el difícil acceso a las tecnologías de avanzadas, la insuficiente comprensión y aplicación del concepto de sostenibilidad, la atención dirigida a los procesos vinculados a la problemática ambiental de los productos y servicios, la poca aplicación de las herramientas de gestión por los empresarios, la no implementación de la contabilidad ambiental, no ejecutar compras públicas sostenibles con un diseño sostenible y responsable a todos los productores de las formas de gestión.

Elementos estos que a criterio de los autores con la función inspectiva y la auditoría aplicada a las formas de gestión en la nación, 
permitirán influir en la construcción de la empresa responsable con el ambiente, ante una cultura empresarial caracterizada en su mayoría por la no adecuada utilización de los instrumentos financieros, no evaluadora de la dinámica del mercado interno y el foráneo, donde no se analizan los niveles de información de cómo opera la competencia empresarial con el empleo de técnicas comerciales, las tecnologías y la innovación para su desarrollo futuro, señalado desde el pasado siglo por autores de la talla de TRIANA CORDOVÍ ${ }^{59}$ y FERNÁNDEZCOMPANIONI $^{60}$, solo utilizadas por las autorizadas a operar en las actividades del comercio exterior como causales endógenas que permitan evolucionar a las formas de gestión del sector estatal cubano al aplicarse la fórmula económica de la: Investigación + Desarrollo + Innovación + Etiqueta-Certificación Ambiental = Empresa Amigable con el Ambiente ${ }^{61}$, como la propuesta que permita insertarse a la nación en mercados más exigentes para contribuir a incrementar la productividad y con ello el Producto Interno Bruto.

Hoy ambas funciones se aprecia por los autores como una sigue constreñida a los ecosistemas de interés (función inspectiva) y la auditoría si está dirigida a controlar las formas de gestión, desde la arista ambiental hasta la contable, lo que la hace más integral. Siendo solo la función inspectora que ejecutan otros organismos de la Administración Pública la que sí ejercita el control a las formas de gestión, de manera mayoritaria al sector estatal.

Lo que deberán ser tenidas en cuenta para futuros estudios desde la ciencia del Derecho que permita contribuir a su adecuada construcción doctrinal y de esta manera coadyuvar a futuras investigaciones científicas por su multidimensionalidad, transversalidad y transdisciplinariedad.

\section{A MANERA DE CONCLUSIONES}

La Inspección Ambiental es una actividad de control, ejecutada por la Administración Pública, pero es menos integral que la Auditoría Ambiental ya que se constriñe al control de los ecosistemas de in-

59 TRIANA CORDOVÍ, Juan. La economía cubana frente al desarrollo sostenible, Memorias 1er Simposio sobre ciencia de la sostenibilidad, La Habana, Cuba, 2013.

${ }^{60}$ FERNÁNDEZ-COMPANIONI, Andrés, La empresa cubana, la competitividad, el perfeccionamiento empresarial y la calidad en, Anuario de la Facultad de ciencias económicas y empresariales, volumen IV, Universidad de Oriente, 2012.

${ }^{61}$ ANTÚNEZ SÁNCHEZ, Alcides y POLO MACEIRAS, Elena. La auditoría ambiental, la industria amigable con el ambiente y el desarrollo sostenible, Revista de contabilidad Cofin Habana, volumen 9, número 2, Cuba, 2015, pp. 135-141. 
terés, por denuncia pública, o por interés estatal, es realizada a través de un plan. En Cuba es ejecutada por el Ministerio de Ciencias, Tecnología y Medio Ambiente, pero se reconoce en el desarrollo de la normativa jurídica que hay otros organismos que controlan aspectos ambientales en relación con el Derecho Urbanístico, el Derecho Agrario, el Derecho Mercantil, el Derecho del Transporte, el Derecho Forestal, y el Derecho Tributario.

La etiqueta-certificación ambiental en el ordenamiento jurídico cubano es un acto administrativo cuya potestad recae en el Ministerio de Ciencias, Tecnología y Medio Ambiente, organismo de la Administración Pública quien al amparo de la potestad inspectora hace la entrega a las formas de gestión estatal del país consideradas como sujetos estratégicos para el desarrollo del comercio internacional en la nación a través de este reconocimiento. Su naturaleza jurídica es reglada. Se sustenta en la Ley n. ${ }^{\circ} 81$ de 1997 y en la Resolución n. ${ }^{\circ} 103$ de 2008, como en las normas complementarias ISO. El interés creciente de los consumidores para adquirir productos respetuosos con el ambiente, permite la oportunidad de su presencia en los mercados para que las formas de gestión ejecución su certificación como empresa amigable con el ambiente para ser más competitivas, ejecutada a través de la auditoría ambiental. Siendo el objetivo primordial obtener beneficios económicos, pero con regulación y control, que permita reforzar la imagen de la marca dentro del marketing ecológico.

La Auditoría Ambiental emergió debido a la contaminación empresarial y su enfrentamiento por el Estado, su génesis fue la auditoría social. Se consolida posteriormente como acción de control practicada por las Entidades Fiscalizadoras Superiores y las Sociedades Mercantiles, posee una construcción jurídica a partir de estar reconocida en Convenios Internacionales, es introducida en los derechos internos mediante los textos constitucionales, las leyes ambientales y de contralorías, brindan solidez y sustento para el desarrollo de políticas ambientales como la herramienta de gestión ambiental. Puede ser voluntaria u obligatoria y manifestarse como una actividad policía, un servicio público u actividad de fomento acorde a su ejecución y consecuencias. Tiene carácter multidimensional, integral y transdisciplinario, su finalidad es la evaluación de la gestión ambiental de la empresa y la certificación de producciones limpias, para realizarla las entidades auditadas deben implementar la contabilidad ambiental y el tratamiento de los residuales de la producción de la empresa. Es un proceso integrado por fases (preparación-ejecución-conclusión) cuyo procedimiento fundamental está regulado en normas ISO y las EMAS. Aparece regulada dentro de los ordenamientos jurídicos como 
una actividad de control o de servicio público dirigida a las formas de gestión, es ejecutada a través de normativas jurídicas ambientales y procedimientos.

La Administración Pública en el país deberá valorar la necesidad de intensificar los estudios de Derecho Administrativo por la interrelación que posee con el Derecho Ambiental, en especial, sobre la actividad de policía, fomento y servicios públicos en la esfera de los particulares y las personas jurídicas, en función de la protección del medio ambiente en los estudios de pregrado y posgrado en la formación en Ciencias Ambientales, que permita configurar y reconocerse a futuro el Derecho Administrativo Ambiental.

\section{REFERENCIAS BIBLIOGRÁFICAS}

ANTÚNEZ SÁNCHEZ, Alcides. Disquisiciones teóricas, doctrinales y exegéticas sobre la praxis de la auditoría como función pública, dirigida a la protección del bien público ambiental para la empresa ecológica, Revista Dos Tribunais Thomson Reuters, número 951, Brasil, 2015.

- La auditoría ambiental: Una revisión y propuestas en clave de su función pública y dimensión empresarial, Revista Iberoamericana de Contabilidad de Gestión, número 26, España, 2015, pp. 3-27.

- La auditoría pública con enfoque ambiental y el tributo ambiental. Aplicación e implementación en Cuba, Revista Internacional Legis de Impuestos, Colombia, 2015.

- El tratamiento jurídico de la etiqueta-certificación ambiental. Regulación en el Derecho Cubano, Revista Iberoamericana de Derecho Ambiental y los Recursos Naturales, número 18, Argentina, 2015.

- Actualización del modelo económico cubano para el ordenamiento jurídico en el desarrollo del Derecho Ambiental patrio, Revista Multiciencias, número 3, Venezuela, 2015.

- The principles of Environmental Law that inform environmental audit, the role of the SAI in the environmental area, Revista del Tribunal de Cuentas de la Unión, número 132, Brasil, 2015.

ALENZA GARCÍA, José Francisco. Potestad de inspección, Revista Actualidad Jurídica Ambiental, España, p. 1894.

AMENÓS ÁLAMO, Juan. La inspección urbanística: concepto y régimen jurídico, editorial Cedecs, Barcelona, 1999, pp. 198-236. 
ARAUJO JUÁREZ, José. Derecho Administrativo General. Servicios Públicos, editorial Paredes, Caracas, 2010.

BASURTO GONZÁLEZ, Daniel. Responsabilidad Social y Ambiental en las Empresas, Revista Política y Gestión Empresarial, México D. F., 2012.

BERMEJO VERA, José. La Administración Inspectora, Revista de Administración Pública, número 147, Centro de Estudios Políticos y Constitucionales, España, 1998, pp. 1-20.

BELLORIO CLABOT, Dino. Tratado de Derecho Ambiental, tomo III, $1{ }^{2}$ edición, Editorial Astrea, Buenos Aires, 2004.

BETANCOR RODRÍGUEZ, Andrés. Instituciones de Derecho Ambiental, editorial La Ley, Madrid, 2001.

CAFFERATA, Néstor. Naturaleza jurídica del Derecho Ambiental, editorial INE-Semarnat, México, 2008.

CÁNOVAS GONZÁLEZ, Daimar. Licencia ambiental y sistemas de responsabilidad, en El Derecho Público en Cuba a comienzos del siglo XXI. Libro homenaje a Fernando Álvarez Tabío, obra coordinada por Ana María ÁLVAREZ-TABÍO ALBO y Andry MATILLA CORREA, editorial de la Universidad de La Habana, 2010.

COSCULLUELA MONTANER, Luis y LÓPEZ BENÍTEZ, Mariano. Derecho Público Económico, editorial Iustel, Madrid, 2007.

CHAMORRO GONZÁLEZ, Jesús María. Los principios del Derecho Administrativo Sancionador y su incidencia en el ámbito de la disciplina urbanística, Revista Fundación Democrática y Gobierno Local, número 5, España, 2010.

DE LUCA, Javier. Introducción al Derecho, 3. a edición, editorial Tirant Lo Blanch, España, 1997.

DÍEZ SÁNCHEZ, José. Función inspectora, 1. ${ }^{a}$ edición, editorial Instituto de Administración Pública, España, 2013.

DROMI, José. Tratado de Derecho Administrativo, 7. a edición, editorial Ciudad, Argentina, 1998.

ESTEVE PARDO, José. Lecciones de Derecho Administrativo, editorial Marcial Pons, España, 2011.

- De la policía administrativa a la gestión de riesgos, Revista Española de Derecho Administrativo, número 119, España, 2003.

- Derecho del medio ambiente, 2. ${ }^{a}$ edición, Editorial Marcial Pons, España, 2008. 
EMBID, Antonio. Precaución y Derecho, editorial Iustel, Madrid, 2010.

HIDALGO CUADRA, Ronald. La terminación convencional del procedimiento y las facultades de inspección en el derecho de la competencia, Revista de Ciencias Jurídicas, número 137, España, 2015.

FERNÁNDEZ RAMOS, Severiano. La actividad administrativa inspectora. El régimen jurídico general de la función inspectora, editorial Comares, Granada, 2002, pp. 21-29.

- La inspección en el marco del control de la aplicación del Derecho Ambiental, Revista Derecho Ambiental, número 24, España, 2000.

- La inspección ambiental, Revista Medio Ambiente y Administración Local, España, 2012, pp. 1-26.

FORSTHOFF, Ernst. Tratado de Derecho Administrativo, traducción de LEGAZ LECAMBRA, GARRIDO FALLA y HERNÁNDEZ MEZA, Lourdes, Inspección y vigilancia, medidas de seguridad y sanciones administrativas, editorial Lex, España, 2010.

GARRIDO FALLA, Fernando. Las transformaciones del concepto jurídico de policía administrativa, editorial Instituto de Estudios Políticos, España, 1958.

GÓMEZ TOMILLO, Manuel y SANZ RUBIALES, Íñigo. Derecho Administrativo sancionador, Parte general. Editorial Aranzadi Thomson Reuters, 2. ${ }^{\mathrm{a}}$ edición, España, 2010.

GARCÍA DE ENTERRÍA, Eduardo y FERNÁNDEZ RODRÍGUEZ. Curso de Derecho Administrativo, tomos I y II, 10. a edición, editorial Thompson-Civitas, España, 2006.

GARCINI GUERRA, Héctor. Derecho Administrativo, editorial Pueblo y Educación, 2. ${ }^{\text {a }}$ edición, La Habana, 1986.

GARCÍA URETA, Agustín. La potestad inspectora de las Administraciones Públicas, editorial Marcial Pons, Madrid, 2006, pp. 35-36.

- La potestad inspectora en el Derecho Comunitario. Fundamentos, sectores de actuación y límites, editorial Iustel, Madrid, 2008, pp. 404-418.

- Potestad inspectora y medio ambiente: Derecho de la Unión Europea y algunos datos sobre las Comunidades Autónomas, Revista Actualidad Jurídica Ambiental, número 54, España, 2016, pp. 1-36.

GORDILlO, Agustín. Tratado de Derecho Administrativo, 8. ${ }^{a}$ edición, editorial Macchi, Argentina, 2006. 
GEZZE, Gastón. Principios generales del Derecho Administrativo, 1. ${ }^{\mathrm{a}}$ parte, Editorial de Palma, Buenos Aires, 1956.

GUILLÉN CARAMÉS, Javier. Régimen jurídico de la inspección en Derecho de la competencia, editorial Aranzadi Thomson Reuters, Cizur Menor, 2010, pp. 237-260.

JORDANO FRAGA, Jesús. La Administración en el Estado Ambiental de Derecho, Revista de Administración Pública, número 173, España, 2007.

LANCÍS Y SÁNCHEZ, Antonio. Derecho Administrativo: la actividad administrativa y sus manifestaciones, editorial Cultural S. A., 3. ${ }^{\text {a }}$ edición, La Habana, 1952.

LÓPEZ MENUDO, E. GUICHOT REINA y J. A. CARRILLO DONAIRE. La responsabilidad patrimonial de los poderes públicos, editorial Lex Nova, Valladolid, 2005, p. 107 y ss.

LORENZETTI, Ricardo Luis. Teoría del Derecho Ambiental, 1. ${ }^{\mathrm{a}}$ edición, Editorial Porrúa, México, 2008.

MACERA, Bernard Franck. El deber industrial de respetar el ambiente, editorial Marcial Pons, España, 1998.

MARTÍN-RETORTILLO BAQUER, Lorenzo. Derechos fundamentales y medio ambiente, Universidad Complutense de Madrid, 2006.

MARTÍN MATEO, Ramón. Tratado de Derecho Ambiental, volumen I,

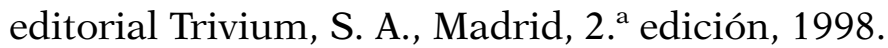

- Derecho Administrativo Ambiental, 6. edición, Editorial Trivium, España, 1997.

MARTINS, Daniel. Introducción al Derecho Administrativo, partes 1. ${ }^{\mathrm{a}}$ y 2. ${ }^{\text {a }}$, editorial Fundación Cultura Universitaria, España, 2004.

MAUER, Harmut. Derecho Administrativo alemán, Universidad Autónoma de México, México DF, 2012.

MATILLA CORREA, Andry. Derecho Administrativo y servicio público. Trazos inconclusos desde una perspectiva histórica, Revista Jurídica, México DF, 2014.

MIRANDA HERNÁNDEZ, Gloria. La potestad inspectora de las Administraciones Públicas, Revista Cuadernos de Inspección del Territorio, España, 2012, pp. 1-21.

MUÑOZ MACHADO, Manuel. Tratado de Derecho Administrativo y Derecho Público General, editorial Iustel, España, 2011. 
NIETO, Alejandro. Algunas precisiones sobre el concepto de policía, Revista de Administración Pública, número 81, España, 1976.

RAMÍREZ SÁNCHEZ, Amed, ANTÚNEZ SÁNCHEZ, Alcides. La responsabilidad administrativa derivada de la inspección estatal sanitaria en Cuba. Una mirada a su régimen jurídico sancionador desde la lucha contra el dengue, Revista Derecho y Cambio Social, Perú, 2015.

REBOLLO PUIG, Manuel. La peculiaridad de la policía administrativa y su singular adaptación al principio de legalidad, Revista Vasca de Administración Pública, número 54, España, 1999.

- Policía administrativa y sanciones administrativas, Revista Ius Publicium, España, 2010.

- La actividad inspectora, editorial Iustel, España, 2011.

ROMÁN CORDERO, Cristian. El castigo en el Derecho Administrativo, Revista Derecho y Humanidades, número 16, Chile, 2010.

RIVERO ORTEGA, Ramón. El Estado vigilante, editorial Tecnos, Madrid, 2000, pp. 79-85.

RINALDI, Gustavo. Seguro ambiental, ejes, Revista Derecho Integral, Argentina, 2012.

PAREJO ALFONSO, Luciano. El Estado social administrativo: algunas reflexiones sobre la crisis de las prestaciones y los servicios públicos, Revista de Administración Pública, número 153, España, 2000.

PARADA, Ramón. Derecho Administrativo, tomo I, 9. a edición, editorial Marcial Pons, España, 1997.

PEÑA SOLÍS, José. La actividad de la Administración Pública: de policía administrativa, de servicio público, de fomento y de gestión económica, Manual de Derecho Administrativo, volumen 3. ${ }^{\circ}$, editorial Colección de Estudios Jurídicos del Tribunal Supremo, Caracas, 2003, pp. 107 y ss.

PEREIRA BASANTA, Jolene. Tesis de Maestría: La autorización ambiental en el marco del procedimiento de evaluación de impacto ambiental: introducción a su régimen jurídico en Cuba, Universidad de La Habana, 2011.

SÁNCHEZ MORÓN, Miguel. Derecho Administrativo, 6. ${ }^{\text {a }}$ edición, editorial Tecnos, España, 2010.

K LOEPFER, Michael. En torno a las nuevas formas de actuación medio ambientales del Estado, artículo traducido por Luciano Parejo Alfonso, en Documentación Administrativa, número 235-236, 1993. 
JORDANA DE POZAS, Luis. Ensayo de una Teoría del Fomento en el Derecho Administrativo, Revista de Estudios Políticos, número 5, España, 1942.

- El problema de los fines de la actividad administrativa, Revista de Administración Pública, número 4, España, 1951.

VAN LEEUWEN, S. El desarrollo de la auditoría ambiental dentro de la INTOSAI, Revista Internacional de Auditoría Gubernamental, número 1, Estados Unidos de América, 2013.

VILLEGAS MORENO, José Luis. Derecho Administrativo Ambiental, editorial Sin Límite, San Cristóbal, 2009.

VILLAR PALASÍ, José. Poder de Policía y Precio Justo. El problema de las tasas del mercado, Revista de Derecho Público, número 48, 1991. 
